\title{
Are the innovation processes in seaport terminal operations successful?
}

Michele Acciaro - Department of Logistics, Kühne Logistics University, Hamburg (Germany); ORCID: 0000-0003-0144-3033

Claudio Ferrari - Department of Economics and Business Studies, University of Genoa (Italy); ORCID: 0000-0002-4339-2871

Jasmine SL Lam - School of Civil and Environmental Engineering, Nanyang Technological University (Singapore); ORCID: 0000-0001-7920-2665

Rosario Macario - CERIS, CESUR, Instituto Superior Técnico, University of Lisbon (Portugal); ORCID: 0000-0002-6922-661X

Athena Roumboutsos - Department of Shipping, Trade and Transport, University of Aegean (Greece); ORCID: 0000-0003-4603-7039

Christa Sys - Department of Transport and Regional Economics, University of Antwerp (Belgium); ORCID: 0000-0001-5962-334X

Alessio Tei - School of Engineering, Newcastle University (UK); ORCID: 0000-0002-1430$828 \mathrm{X}$

Thierry Vanelslander - Department of Transport and Regional Economics, University of Antwerp (Belgium); ORCID: 0000-0001-5213-3444

\section{Funding}

This work was supported by BNP Paribas Fortis Chair Transport, Logistics and Ports. The authors wish to thank the research partners of the international consortium of Universities involved in the data collection of port-related innovation cases.

\section{Acknowledgement}

This article is a revised and expanded version of a paper entitled "Innovation processes in seaport terminal operations: Insights from an empirical analysis" presented at the 14th World Conference on Transport Research, Shanghai, China; 10-15 July 2016.

Corresponding author: Claudio Ferrari, Department of Economics and Business Studies, University of Genova, claudio.ferrari@economia.unige.it 


\section{Abstract}

The maritime and port sector is widely considered conservative concerning the ability to introduce innovation in respect to other industries. This may be due to the lack of cooperative interactions among the several players involved. It does not mean that innovation does not occur in this industry. Along with some technical also managerial, organizational and cultural innovations take place in the sector. The literature has considered the assessment and effects of the adoption of particular innovation, but still few studies underline the innovation path in a broad sense with a specific focus on terminal operators. The present paper aims at filling this gap through a field analysis grouping together case studies developed in different world regions and examining the adoption path of innovation through a mix of three different techniques (i.e. the H- and I-indexes; a System Innovation Analysis; and a Qualitative Comparative Analysis). Research outcomes underline how, even if no unique recipe for success can be found, specific factors (e.g. a ranking of innovation objectives, coordination among actors and institutions) can influence the achievement of success. The analyses allow suggesting strategic and policy advice that may help link in a better way the innovation drivers with their actual effects.

Keywords: Innovation path, Seaports innovation, Terminal operator, Qualitative Comparative Analysis, H- and I-index, System Innovation 


\section{Introduction}

Innovation is an essential element of economic activities in order to foster long-run growth. As underlined in De Martino et al. (2013), innovative paths are becoming relevant drivers for enhancing the competitiveness of any firm, independently of their respective market. The effect of the innovation differs depending on the specific industry: while some markets (or firms within the same market) can react slowly to the introduction of a specific innovation, others can benefit more or are faster to promote it. Kandampully (2002) showed how service organizations could benefit more by the introduction of innovation even if the kind of innovation can affect their capability of fostering this innovation. As innovation differs from sector to sector (Hipp and Grupp, 2005), it is important to focus on the innovative process to understand conditions that might support the different stages of the innovation process itself. Cantner et al. (2010) underlined how in a regional system, innovation networks might increase the benefits generated by a certain innovation. The role of an innovation process is central in the macroeconomic growth theory. The first economist that centred in the economic theory his reflections around the role of innovation and the relationship among innovation and entrepreneurs was J.A. Schumpeter who defined innovation as "the setting up of a new production function" (Schumpeter, 1939). More recently, Sundbo (1998) emphasizes the essence of innovation as "an effort made by one or more individuals that produces an economic gain".

\subsection{Definition of innovation}

In accordance with Schumpeter (1939), innovation is "a linear path in which the economic gain assures an irreversible mutation of the competitive conditions". This definition has deeply affected economic thought. An example is the Solow Model in which technological changes are based on "linear" progressions that directly impact on the production function. In this approach, failure in innovation can be seen as the presence of high unrecoverable costs (e.g. sunk costs related to the innovation development) that hinder the successful implementation of a given innovation. On the other hand, as underlined in Arduino et al. (2013) and Roumboutsos et al. (2014), other scholars (e.g. Rogers, 1962) described innovation initiatives as outputs of the dynamics of complex systems made by a plurality of actors that affect the success and the uptake of a given innovation. Following this approach, links and communications among the actors belonging to the same environment (e.g. port and maritime sector) influence the development and the successful implementation of any innovation. For instance, Powell and Grodal (2005) underline the importance of collaboration in achieving the success of an innovation thanks to the interactive learning processes.

This stream of thoughts has been well accepted in the academic literature in which communities tend to have a great influence on the economic behaviours. For this reason, several studies (e.g. Hall and Jacobs, 2010; Cahoon et al., 2013) use a systemic approach to study innovation in the port industry. In line with this research track, the innovation success is strictly depending on the interaction among the players; and it can be either organizational or technological, potentially 
impacting on both the product and the production process. Moreover, an innovation can result in a reduction of costs or in an increase of revenues of one or more actors involved in the innovation process; and it normally impacts on the productivity of the innovator and its followers. In addition, innovations can be the results of either monetary or non-monetary factors, such as cultural or political, instead of driven by simply commercial purposes. Moreover, innovation processes can lead to different results depending on the sector characteristics: many authors underline how the definition and exploitation of innovation in service industry might be different from the classic outcome in the manufacturing sector (e.g. Gallouj and Weinstein, 1997; Hipp and Grupp, 2005), leading to different kinds of innovation (for instance, not strictly technological). Moreover, according to Mothe and Uyen (2012), non-technological innovation at least in the service sector - can lead to technological advancements as second achieved goal: depending on the stage of advancement, innovations initiatives can promote further innovations.

According to Acciaro et al. (2014a), innovation initiatives can be differentiated in two distinct categories: incremental and radical, depending on the possibility of having marginal adjustments caused by the innovation or drastic changes in the market. Eventually, Sys et al. (2015b) discussed differences among innovation typologies more broadly, while Vanelslander et al. (2016) added two more categories that might differentiate effects of innovations: apart from radical and incremental, innovation can be also systemic (integrating multiple independent

initiatives that must work together to perform new functions or improve the overall performance) or modular (bringing about a significant change in concept within a component, but links to other components or systems remain unchanged and the impact is fairly low).

\subsection{Innovation within the port sector}

With respect to the transport sector, the International Transport Forum (2010) registered less proactivity of transport firms in comparison with other industries where it comes to actually implemented innovation. Despite this, several research projects (e.g. Aronietis et al., 2009; Kapros, 2010; Arduino et al., 2011b) discuss many innovation concepts introduced in the transport sector in order to achieve results in terms of general performance, not just economic ones. Furthermore, Arduino et al. (2011a and 2013) highlighted the difficulties of introducing innovation in the transport sector. Even the push for sustainable transport is partially mitigating those difficulties (e.g. Thorpe and Namdeo, 2016).

Concerning the maritime and port sector, innovation is strategic in order to keep national shipping and port industries competitive (Jenssen, 2003), maybe in consequence of the increasing competition that characterises the industry. Doloreux and Melancon (2008) show similar results for local industries. Despite the importance of the sector for the local and national economies (e.g. Coppens et al., 2007; Bottasso et al., 2014) and the benefits of implementing innovation within the markets, it seems that the port and shipping industry have not fully found their way to introduce innovative solutions within the sector. In accordance with Acciaro et al. (2014a) and Arduino et al. (2014), this might be due to the internal characteristics of the market 
and the needed but insufficient relationships among the different actors of the entire logistics chain. An example of this needed coordination is given by De Martino et al. (2013), in which innovation in seaports is strictly linked to the innovative solution exploited by the logistics providers in their delivery choices: a large number of innovation initiatives in seaports are generally related to market changes at both demand and supply side. Concerning this issue, it is important to underline that while in other sectors, social innovation (Volberda, 2014) represents the majority of successful innovation - such as in most manufacturing sectors -, barriers to collaboration in the port industry make technology-related innovation a predominant element. Thus, current literature often focuses more on the assessment of investments (Zheng and Negenborn, 2017) linked to upgraded facilities capable of improving environmental performance (Cui, 2017) or port congestion (Jian et al., 2017) rather than on the evaluation of innovative processes.

Considering port-related innovation, an extended literature has recently focused on the assessment of innovation focusing on the mitigation of port environmental effects (for instance Lam and Van de Voorde (2012) and Lam and Notteboom (2014) focused on the implementation of green ports policies, while Acciaro et al. (2014b) focused on energy management innovations), port performance (e.g. Bottasso et al., 2014), or logistics issues (e.g. De Martino, 2013). Nevertheless, while all these studies focus on specific characteristics related to a particular innovation goal (or process), only few other papers (e.g. Arduino et al., 2013 for the definition of innovation success; Acciaro et al., (2014a) for the assessment of environmental innovation; Vanelslander et al., (2016) for the determination of the success conditions) analyse the elements affecting the interactions among the participants to the innovation process and the characteristics that may assure a successful adoption path.

In this regard, this paper assumes a particular role for a better understanding of the innovation champion that represents the promoter (or the exploiter) of the innovation process (e.g. Vanelslander et al., 2016) and then the "leader" of the innovation eco-system, that is represented by the physical and virtual interaction among the actors involved in the innovation process. Thus, while several papers investigate specific innovation case studies or investment patterns, focused on technical advancements, not many studies focus on understanding conditions and other factors (e.g. business environment, relationship among involved actors) that bring innovation to succeed in the port sector or that evaluate the achievement of specific goals of a planned innovation. The current paper tries to fill this gap.

\subsection{The proposed analysis}

The literature has considered the assessment and effects of the adoption of particular innovation initiatives in the port sector (e.g. Arduino et al., 2011b), but still few studies focus the attention on the innovation path in a broad sense aiming at understanding which interactions among the players may foster a successful implementation of the specific innovation initiative. The present paper aims at bridging this gap through a field analysis grouping together a set of deep-sea 
terminal operator case studies. The cases considered are a sub-set of a major research initiative, further referred to as the BNPPF project $^{1}-$, on innovation processes in the port industry, identified between Autumn 2013 and Spring 2015, in order to better understand the innovative processes in the port industry. Thus, basic information for the proposed research is based on the data collected for the BNPPF project (for main details, readers may refer to Sys et al., 2015a). In the wider BNPPF project, cases were selected through a desk analysis and contacts with various port and terminal operators in order to highlight main ongoing innovation initiatives in several main ports. In order to achieve the research goal of this specific paper, data and background information, as well as interviews. While the overall BNPPF project focused on 75 different innovation cases concerning several main ports (Antwerp, Genoa, Lisbon, Los Angeles, Piraeus, Singapore and others) and port-related activities, the present paper focuses on 19 cases (out of the wider group of 75 innovation cases) involving deep-sea terminal operators (i.e. private companies located in either a private port or a landlord port) and the critical issues related to the innovation development. . Eventually, while the geographical scope shows the distribution of the cases, it is worth to underline that the selection has been done based on the cases found in the industry and it is not connected to geographical patterns.

The characteristics of the innovative concepts can be found in Annex 1.

The paper is structured as follows. After this introduction, Section 2 provides the methodological approach for the analysis that is conducted in this paper. Section 3 outlines the results of the analysis. Finally, section 4 draws conclusions from the findings.

${ }^{1}$ This wider research initiative was funded by BNP Paribas Fortis (BNPPF). 


\section{Methodology and cases}

In accordance with Arduino et al. (2013) and Roumboutsos (2015), innovation processes should be analysed through a multi-layer approach in which several distinctions should be made. For the purpose of this paper, general assumptions following the existing literature were developed.

\subsection{The performed analyses}

The methodology used in this paper is a combination of three different methodologies applied in the last years to the mentioned port terminal cases by some authors: the I- and H- index extensively discussed in Acciaro and Sys (2016), the System of Innovation Analysis (SIA) to port innovation, applied by Roumboutsos (2015) and Roumboutsos et al. (2014), and the Qualitative Comparative Analysis (QCA), performed by Vanelslander et al., (2016). Figure 1 shows the process logic driving the analysis: the three different techniques are complementary and they allow answering the main research questions of this study through triangulation (see for example Jick, 1979). In fact, the consistency among the "planned" innovation objectives and their degree of success together with the analysis of the factors that influence the achievement of the success can be analysed only through a composite methodology. In particular, the combined outcome of the applied techniques will be use to underline the degree of success of the studied innovations (in comparison with the stated goals) and if the systemic interactions and specific factors can influence the achievement of the success.

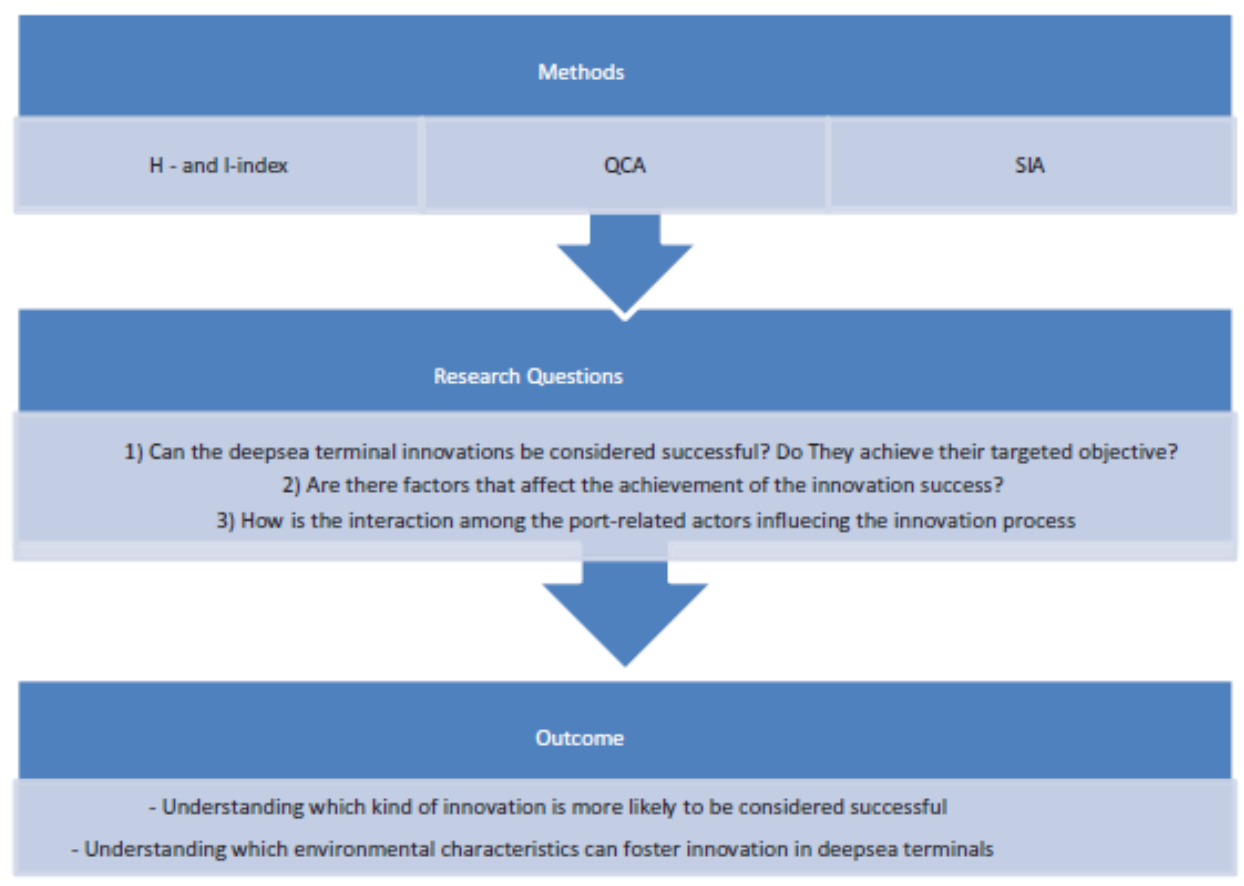

Figure 1. Analysis structure. 
Thus, the first applied methodology is an extension of the method developed in Acciaro et al. (2014a) and it is fully described in Acciaro and Sys (2016). It consists of the assessment of success of innovation based on the extent to which such innovation has contributed to the achievement of a certain set of objectives ${ }^{2}$. The method originates from the observation that innovation is implemented with a specific purpose or set of purposes, e.g. to improve efficiency, to increase market power, or to respond to a new regulation.

As such, its success can be defined only as a measure relative to the objectives the innovation aimed at achieving. Those objectives may differ substantially from industry to industry and from firm to firm, as they are embedded within the characteristics of the industry and each firm's strategy. Thus, through an iterative method that involves the use of a survey and a sufficiently large number of innovation initiatives, it is possible to develop two rankings: one that identifies the importance of each objective for the firm or the group of firms under analysis and a success ranking of the innovation initiatives surveyed with respect to each objective. If an innovation process is conducted, one would expected that important objectives are priorities, so that innovation aiming at targeting such objectives is more successful in delivering the expected results. Therefore, it is possible to assume there are some similarities between the two rankings. These rankings can be analysed using a homogeneity index (H-index) that allows assessing whether there is accordance among respondents on the importance of each objective and on the success of each innovation initiative. High heterogeneity is indicative of a sample that is not aligned in terms of strategy. While the H-index focused on the similarities, the key idea of the Iindex is to be able to provide a synthetic indicator of the differences between rankings. The interpretation of the I- and $\mathrm{H}$ - indexes is rather intuitive. Ideally, when the I-index takes a null value for an innovation or an objective, it implies that in general there is an identity between importance ranking and success ranking. When the value is positive, it indicates that the success ranking is lower than the importance ranking, and when the value is negative, it implies that the success ranking is higher than the importance ranking (Acciaro et al., 2014a; Acciaro and Sys, 2016).

To analyse the innovation process smoothness, as only a limited amount of information is available per innovation case, a good method to deal with such situation is QCA (Vanelslander et al., 2016). This method keeps the middle between a qualitative and a quantitative approach and according to Thiem and Dusa (2013), it is one of the most influential methods to evaluate innovation. With this technique, variables on innovation are combinations of innovation success / failure factors and actors. They belong to the three stages - initiation, development and implementation - through which an innovation initiative usually develops. This approach allows assessing which innovation initiatives will generate which chain impacts, and which conditions

\footnotetext{
${ }^{2}$ In the presented study, a set of 31 objectives were found. The objectives were divided in three main categories: economic, environmental and social.
} 
will conduct actors to innovate, or prevent them from doing so, and finally also how governments can stimulate innovation. Cases are considered combinations of attributes. They are coded for having membership in a set of causal conditions. The information is formalized in a truth table, and Boolean logic is used to reduce the table to a number of sufficient and necessary conditions. Set-theoretic methods allow stripping away elements that are not causally involved with the outcome. Furthermore, these methods allow measuring the "coverage," i.e. the relative importance of different paths to an outcome, and "consistency," i.e. what proportion of observed cases is consistent with the pattern. (Fiss, 2008). QCA offers a systematic approach that at the same time can examine extensive numbers of different combinations but does not disaggregate the case like a variable-based approach would (Fiss, 2008). As described in Vanelslander et al. (2016), the results of the QCA are given by a fuzzy set analysis that allows calculating consistency and coverage scores: in other words, the QCA outcome gives an indication of the subset of conditions that might foster an innovation initiative's success.

The SIA views innovation within the "system" it is introduced in, considering the complexity of the process, characterized by reciprocity and feedback mechanisms, which determines the success of innovation (see for example Lundvall, 2010; Nelson, 1993; Edquist, 1997). As discussed in Arduino et al. (2013), SIA provides a means to identify a set of external factors (the so-called 'institutional environment' and 'rules') and the actors involved in the innovation being analysed, and it identifies for each innovation a range of influences' from the environment (Roumboutsos, 2015; Roumboutsos et al., 2014). Extending on Woolthuis et al. (2005) and Edquist and Chaminade (2006), with consideration on innovation failures, Roumboutsos et al. (2014) included the study of positive effects as well as the consideration on the innovation process over the different stages of development. The consideration of the type of innovation (see section 2.2 below) guides the identification of actors involved. The methodology is further elaborated in Roumboutsos (2015). More specifically, for each innovation, interactions among different kinds of actors (e.g. shipping companies, stevedores, etc.) were ranked for different layers of analysis (e.g. kind of innovation, innovation initiatives' predominant aspects) and in relation with different environmental attributes (e.g. institutions, rules, infrastructures). Each interaction among actors - and within different environment - is depicted by dependency vectors qualified in the range $[-3,+3]$. The SIA allows for a better understanding of both the relationships developed among actors that influence the innovation process and of the interactions among players that are important in order to foster innovation (Roumboutsos, 2015).

\subsection{Selected innovation cases}

Among the 75 cases referred to in section 1.3, 13 innovation initiatives were selected as affecting mostly the deep-sea terminals. The set of cases involves initiatives applied in several geographical regions (e.g. Southern Europe, Northern Europe, Asia, and North America) and implemented by different companies, thus assuring a diversification also in the implementing 
firms' characteristics. The sub-selection of 13 innovation initiatives has been done taking into consideration the innovation that affects the terminal operations, while the wider sample of 75 innovation cases also concerns activities that do not directly affect operations at terminal level. Moreover, some of the 13 innovations initiatives, as also described below, are present in multiple ports, increasing the number of studied cases to 19 (see Annex 1).

Below, the selected innovation cases (described in detail in Sys et al., 2015) are briefly introduced:

1. Pre-notification at deep-sea terminal - For deep-sea terminals, it is crucial to know in advance for which inland terminals the incoming containers are destined. Based on this information, the stacking / shuffling can be optimized at the deep-sea terminal.

2. Automated stacking cranes - Increasing density of the yard influences its performance: such system is currently under development.

3. All weather terminals (7) - These provide a completely covered logistics service for moisture- and weather- sensitive cargoes. By being handled under covered conditions, the transhipment takes place in a controlled environment. This development ensures less damage to the cargo, and operations are done in a safer environment.

4. Tandem lift - To avoid bottlenecking these flows, the process of loading and unloading containers is speeded up by coupling two or more containers in one lift. In this way, the efficiency of berthing operations is significantly increased.

5. Straddle carriers - The replacement of diesel engines of a straddle carrier by CNG engines.

6. Weighbridges - Weighbridges are installed at the terminal in order to measure trucks' axle loads.

7. Full automated gate - Automatic gate in and out cycle for treating trucks (including automatic loading and unloading of trucks).

8. Truck appointment system - Streamlining truck volumes through agreements with "time slots".

9. Terminal carbon footprint tracking - Tracking of emissions developed by the terminal.

10. Carbon footprint assessment (Port Authority) - Evaluation system of carbon foot print at port level.

11. Carbon footprint assessment (Terminal Operator) - Evaluation system of carbon foot print at terminal level.

12. Autotrakker - An IT technology option using low-powered (eye safe) laser/scanners. The main purpose of the application is to give right cargo measurements, to avoid inaccurate billing and damage for either loads or ships.

13. Offshore Single Point Mooring - Off-shore platform capable of rationalising the liquid bulk activity (oil) moving out from the city to the loading/unloading operations connected to the biggest ships. Main goals are connected to the social acceptance of the liquid bulk terminal and the increase of productivity. 
Concerning the innovation cases used in the analysis, some further characteristics should be underlined.

First, commercial innovation initiatives have to be separated from those that assure welfare improvements, because the aim of the outcome may lead to different interactions among the system players. The subset of innovations initiatives considered in the present paper is composed solely of commercial innovation initiatives.

Second, innovation initiatives may be classified by the main aspect that characterizes them: technological, organisational, cultural, and managerial. This is relevant since different types of innovation might again bring different interactions among the actors. Table 1 gives an overview of the 19 case assessments. Given the all-weather terminal, Type I (Technological - unit change) is the most prevalent type of innovation. Technological, Managerial, Organisational, Cultural business change (Type III) and market change (Type IV), represent $31.57 \%$ of the cases; while Type V (Managerial, Organisational, Cultural - market change) accounts for $15.79 \%$ of the cases. Concerning this issue, it is important to underline that, while all the studied innovation cases are technology-based, some of them could also be linked to social innovation wherever they "mean a new way of managing, organizing and working" (Volberda, 2014). This element is quite important to identify the "innovation eco-system".

\section{Table 1 - Innovation Typologies}

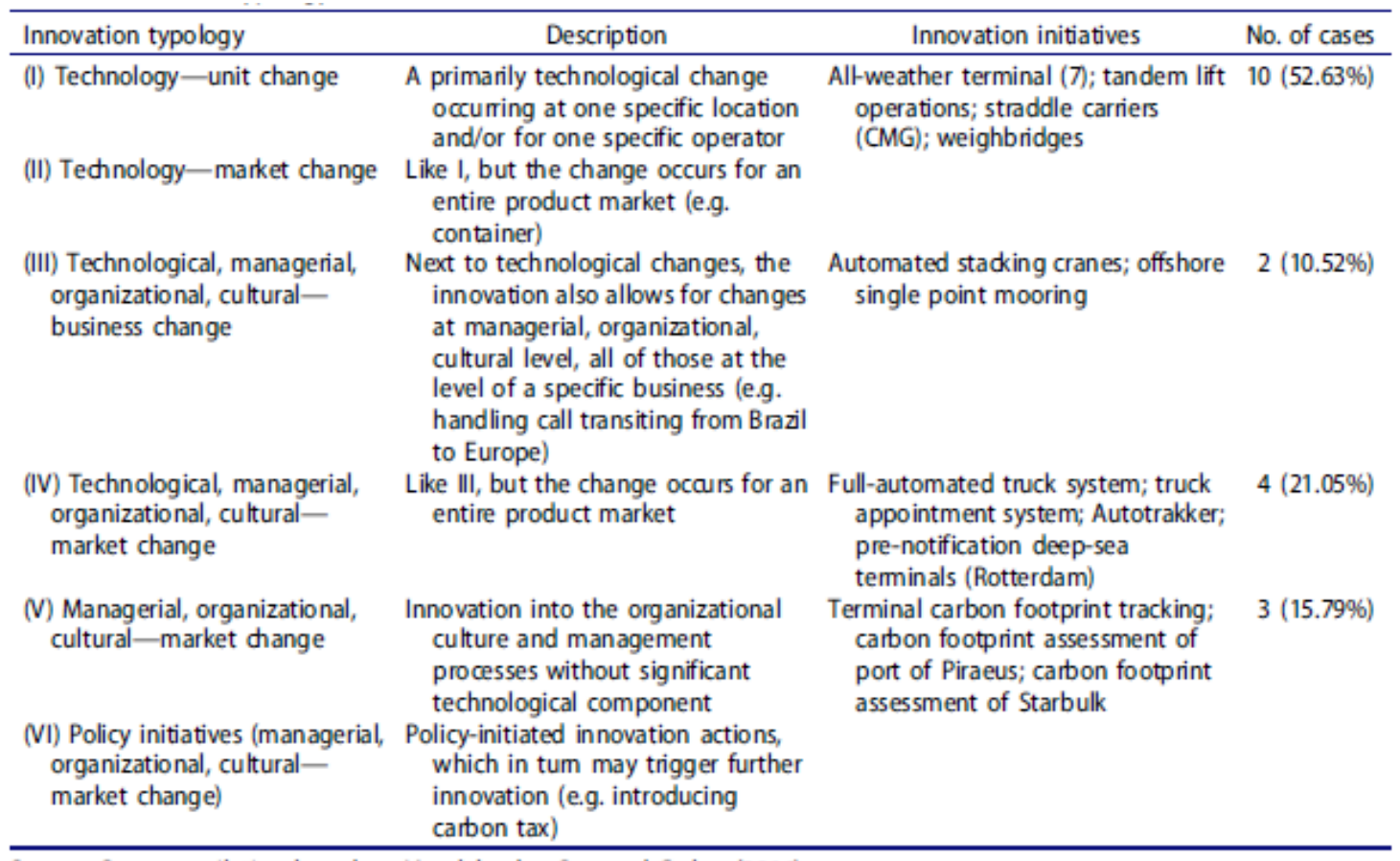

Source: Own compilation based on Vanelslander, Sys, and Carlan (2016). 
Third, the outcome might be affected by the "innovation stage" (e.g. initiation, development, implementation) and the potential presence of barriers into the market. With "innovation stage", reference is made to the life-cycle phase of the innovation - initiation (5 cases), development ( 3 cases) and implementation (11 cases) - because depending on different phases, the same innovation might be considered either successful or not yet successful. Barriers are represented by factors that may slow down the success of the innovation and they can vary depending on the type of innovation and on the phase of implementation (see Annex 1).

Among the abovementioned innovation actions, radical innovation initiatives ( 1 case) are rare in the deep sea terminal sector, while incremental (4 cases) and system (4 cases) innovation initiatives have a significant share of the total, even if modular innovation (10 cases) represents the majority of the studied innovation initiatives. (see Annex 1) ${ }^{3}$.

Ultimately, many innovation initiatives concern environmental initiatives (or they have also green effects) and this will be a major discussion point to take into account for further considerations.

\section{Research outcome}

As outlined in section 2, the three methodologies have been applied in order to better understand the innovation process. Through the combination of $\mathrm{H}$ - and I- indexes, it is possible to assess the goals of innovation and the achievement of its success. The QCA complements the previous results, by highlighting successful / failure factors; lastly the SIA focuses on the interactions that are included in certain innovation paths.

Ideally, it would be expected that important objectives have the same ranking in terms of success, and at the same time high levels of success are to be achieved for similarly important objectives. For each innovation, high differences in the similarity between success ranking and importance are an indication of either innovation failure - success is not achieved in the same relation to importance (positive score), or incidental success - and success is achieved for objectives that are categorised as not particularly important.

Considering the main results, Table 2 shows the difference between objectives for the considered cases (Annex 2 shows in detail the average success on three layers: economic, environmental and social added-value). Since each objective (i.e. success ranking and importance) has been scored in a range between 1 and 5, the differences are then between -4 and 4 . It is possible to observe

\footnotetext{
${ }^{3}$ The term 'incremental' corresponds to a small change to existing products/procedures, 'system' to multiple independent innovations, 'modular' to a significant change in concept within a component while 'radical' indicates a breakthrough in the specific field.
} 
that most innovation initiatives are concentrated around 0 , which indicates that the difference for these innovation initiatives between success ranking and importance ranking is very low.

Table 2 - Success vs Importance

\begin{tabular}{|c|c|c|c|c|c|c|c|c|c|}
\hline Differences & -4 & -3 & -2 & -1 & 0 & 1 & 2 & 3 & 4 \\
\hline No. of innovations & 2 & 5 & 10 & 12 & 16 & 9 & 6 & 1 & 1 \\
\hline Avg. value & $1 \%$ & $1 \%$ & $8 \%$ & $6 \%$ & $73 \%$ & $5 \%$ & $5 \%$ & $0 \%$ & $0 \%$ \\
\hline St. dev. & 0.023 & 0.021 & 0.195 & 0.060 & 0.216 & 0.066 & 0.088 & 0.008 & 0.005 \\
\hline General differences & \multicolumn{4}{|c|}{ - } & 0 & \multicolumn{4}{|c|}{+} \\
\hline Frequency & \multicolumn{4}{|c|}{$16 \%$} & $73 \%$ & \multicolumn{4}{|c|}{$10 \%$} \\
\hline
\end{tabular}

Considering specific research outcome, most notable in the sample are Autotrakker, with $21 \%$ of the frequencies showing a negative difference (i.e. success is higher than importance), and "Offshore Single Point Mooring", where $89 \%$ of frequencies are negative values. Among those innovation initiatives where success is not ranked equal to importance, are Tandem Lift and Carbon Footprint at port and terminals. This latter issue confirms that environmental innovations tend to obtain negative scores (as in Acciaro and Sys, 2016) because for being innovative it is just necessary to comply with regulation.

In order to generalise the results, it is important to be able to compare the innovation initiatives, and ensure there is some homogeneity among respondents. The analysis shows that there is quite some variety in the respondents' agreement, indicating that the innovation initiatives have somewhat different profiles. The homogeneity index $(\mathrm{H})$ ranges from 18 to 100, where the lowest value indicates heterogeneity in the replies. In particular, economic objectives show highest heterogeneity, while social and environmental objectives are more homogeneous.

The I-index analysis shows that deep-sea innovation tends to perform relatively well as scores are mostly in the negative area, implying that success is achieved. However, the negative score indicates that success is achieved on issues that are comparatively ranked less important. This phenomenon is less evident for the objectives listed under economic added value. In a confrontation with a multitude of objectives, the economic ones tend to rank with a positive score, while for deep-sea innovation, they rank slightly negative, indicating that there is a better alignment between the degree of success and the importance assigned to some strategic objectives (see also Annex 2). Particularly striking is that these innovation initiatives appear to fail on growth and market share expansions. This is not surprising as growth in international shipping is typically beyond the control of a single company and market share is very hard to gain in the global competitive arena.

Concerning the QCA, success is measured based on a weighted average of the above mentioned economic, social and environmental criteria, scored by the assessed companies. With the entire 
set of 40 cases (described in Vanelslander et al., 2016), it turns out that no unique 'recipe' for innovation success does exist. However, some combinations of variables can be identified that lead for certain groups of cases to a higher chance of success. Overall, important variables turn out to be infrastructure, soft-institutional (i.e. social values) and hard-institutional (i.e. rules and law) issues at the initiation stage, and infrastructure at the development and implementation stages (Vanelslander et al., 2016). All four groups seem to be composed of both physical innovation as well as virtual innovation (e.g. 'EDI') (Carlan et al., 2017; Roumboutsos et al., 2016). Hence, the latter is not a distinguishing criterion.

According to Vanelslander et al. (2016) four groups of elements can be underlined as the ones most influencing the innovation success in deep-see terminals (Table 3). The first group relates to the terminal alignment with infrastructure, both at the level of development and implementation. Terminal cases complying with this category involve Tandem Lift operations, Autotrakker and All-weather terminals.

A second group refers to shipping line-related variables (fzQCA2): in particular, shipping line alignment with infrastructure, both (again) at development and implementation stage. Tandem Lift operations and All-weather terminals in The Netherlands and Spain as terminal innovations qualify here.

A third group highlights the role of social values (fzQCA3) impacting the innovation champion at all the development stages of the innovation. In this category, find Automated Stacking Cranes and the implemented All-weather terminals in The Netherlands as terminal cases.

The fourth and final group of the variables featuring consistent success looks at the innovation champion (fzQCA4) during the initiation stage, focusing on hard institutions and infrastructure. Again, Automated Stacking Cranes and All-weather terminals (NL, BE) qualify here.

Table 3 - Conditions for success

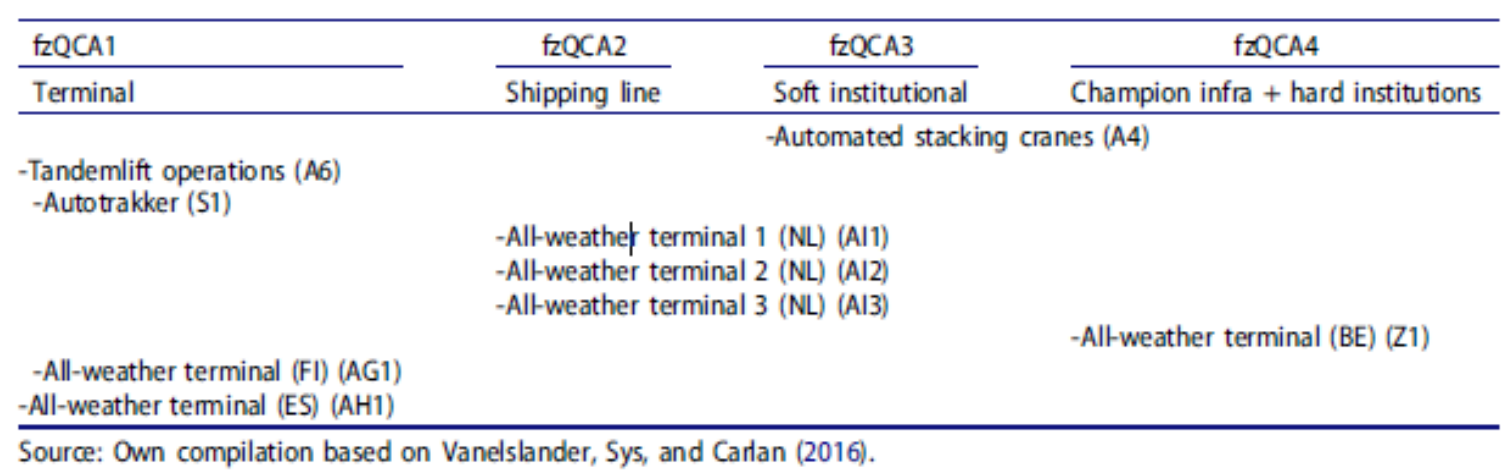


Moreover, Table 3 shows that the conditions for success for the second and third all-weather terminal build in The Netherlands are no longer related to the hard institutions. An explanation might be found in the learning experience. Clearly, the second fast movers (BE, FI, ES) cannot roll out the set-up of the innovative initiative in the same manner as the innovation champion.

Roumboutsos (2015) with SIA, indicates that for the "Autotrakker" and the "Offshore Single Point Mooring" innovation cases, there was no financial involvement. In addition, in the case of the Autotrakker, the innovation champion is not the immediate beneficiary (terminal). This fact provides justification with respect to the reason of lesser importance attached to the actual success as otherwise the terminal operator would resume leadership.

Eventually, the open or closed character of an innovation initiative does not seem to have an impact. Focusing on the conditions leading to a successful innovation (QCA analysis), it turns out that four groups of conditions contribute to success, i.e. the combination of variables resumed above. Moreover, most of the selected terminal cases comply with several or even all groups of factors: meaning that several combinations of conditions have contributed to their success.

Thus, it is possible to underline that, even if no unique recipe for success can be found, some variables could influence the probability of success of a specific kind of innovation. Moreover, some interactions among the port actors might influence the odds. For this reason, findings from the SIA contribute to better understanding the innovation path. From a system point of view, actor co-operation plays an important role. In fact, findings also suggest the difficulty in achieving aligned objectives within the port terminal stakeholder network and the potential need to invest effort in promoting the objectives of the innovation to be applied. Thus, results underline the importance of a better evaluation of the fostered innovation initiatives in order to better understand the potential of the pursued innovations.

Considering SIA, as expected, the cases for which there is high concentration in the range $[-1,1]$ are the cases for which a high degree of consensus exists within the stakeholder network with respect to the innovation to be implemented. The Autotrakker is a case pushed forward by market demand overcoming negative stakeholders, who did not agree on the importance of the objective, as also underlined by the I- and $\mathrm{H}$ - index analysis. A final point of interest, with respect to input from the SIA (Roumboutsos, 2015), is the fact that the Fully Automated Truck System went ahead based on the strength of the innovation champion. Ex-post, the innovation champion has still not convinced other stakeholders of the importance of the innovation.

Eventually, in all the three performed analyses, no differences were found among innovation cases implemented in different countries showing a common path for all the analysed operators spread worldwide and all the analysed companies seem to continuously progress in implementing new solutions in order to deal with the changing market requirements.

\section{Discussion and managerial implications}


Summing up the outcomes of the three methodologies, it is possible to underline some common issues. Port innovation initiatives often come up as incidental success (not perfect alignment between objective and success) in which several groups of factors influence the achievement of the success without geographical distinctions among these elements. Moreover, often the interactions among actors - as well as the presence of a collaborative environment - seem to be a key element in the innovation path, especially when the innovation champion is involved. Lastly, the role of private firms as innovation champions in the sector is evident; the private nature of innovators probably explains why almost all the cases taken into consideration have been internally evaluated but at the same time they did not put through a cost-benefit analysis evaluation.

For these reasons, several managerial implications can be drawn from the analysis above. First of all, the role of the cluster and the need for cooperation might be linked to the need of a "port innovation leader" capable of both introducing an innovation and of coordinating the efforts related to the innovation development. Standalone innovative processes seem to be less effective in achieving success. Second, it is interesting to notice as in other transport fields, innovation is actually driven by a general Research and Innovation form of aggregations (e.g. the Shift2Rail scheme in the EU rail sector) in order to generate collaborative environments and standards of investment. This issue seems also to be connected to research (e.g. Jansen et al., 2006) that links the effectiveness of innovative processes to both organisational and environmental elements. Third and finally, some of the innovations seem to be linked to a wider environment that overpasses the port boundaries (e.g. supply chain through both horizontal and vertical collaboration) needing innovation champions to increase their size. This latter element seems to be of particular importance for those innovation initiatives that are affecting different port-related markets (e.g. specific terminal characteristics) and they might become even more important with the full development of smart shipping (e.g. Stopford, 2015).

\section{Conclusions}

Innovation is a strategic factor that deeply affected the seaport industry during the last decades. Examples of its importance can be found in new terminal organization. Despite this importance, the port industry ranks as one of lesser innovative economic sectors in the International Transport Forum's report on innovation (ITF, 2010). Nevertheless, the international joint research here presented evidence that the perception about the maritime and port sector being less innovative when compared to other sectors no longer remains intact. In particular, innovation at terminal level is considered essential to remaining competitive. The study has been developed through a set of deep-sea terminal innovation initiatives - included in a wider investigation - aiming at underlining both characteristics of the studied innovation initiatives and their innovation processes. These comparisons allow better understanding of the elements that contribute to define these innovation initiatives as successful, variables conditioning the success 
and the environmental characteristics that might facilitate the achievement of the innovation goal. Moreover, specific differences and commonalities among the studied set of cases have been underlined (see Roumboutsos, 2015).

Case-based analysis allows getting an idea whether the deep-sea terminals are preparing themselves for new economic, environmental and social requirements. With few exceptions, the majority of the innovation cases are demand-driven (e.g. for the container terminals due to the scale increase, for the break-bulk sector to meet the ever-increasing demand for more efficiency). Moreover, successful innovation initiatives are often linked to the pursued objectives that might be achieved. The analysis underlines the strategic alignment between innovation success and importance of the objectives the innovation aims at achieving for the innovator. Furthermore, Giuliano et al. (2016) point out as innovation in seaport industry is normally pursued by private companies without a proper economic assessment process (i.e. Cost-Benefit Analysis) and this can be explained by the role of the innovation champion that normally exploits the innovation internally as outcome of an industrial process.

Despite the mix of methodologies used in this study, no unique recipe came out from the research in order to foster innovation success. Nevertheless, the results show that most innovation initiatives achieve levels of success that are higher than the corresponding importance ranking attributed to them. This somewhat incidental success suggests that there is room for ensuring that resources are not invested in innovation that achieves strategic aims that are only marginally valued by the company. Moreover, some specific factors seem to impact on the possibility to achieve the innovation success. Among these factors, the alignment between the companies involved in the innovation to specific issues (e.g. soft institutions) or specific actors (e.g. innovation champion) might foster the success. Considering these results, specific intercompany and intra-company strategies might be set up in order to incentives innovation paths (e.g. shared innovative infrastructures). Moreover, adaptive innovation strategies might help foster innovation processes better than rigid approaches. Furthermore, as underlined by past studies for the service industry (e.g. Mothe and Uyen, 2012) also in the port sector nottechnology-driven innovations might easily achieve success, bringing the innovator champion to further technological innovations.

In terms of policy advice, the research highlights two possible levels of intervention. First, since hard institutions have an impact on the chances of success, it is important to develop a clear system of rules and a "level playing field" (i.e. a fair competition environment) for port players in order to avoid opportunistic (and conservative) behaviours. The second one, somehow depending on the former, refers to the role of co-operation within the port community; the role of a public authority in this sense should increase the awareness that a seaport community, when behaving as a milieau innovateur - thus exploiting the agglomeration scale economies and the potential wide synergies among the local actors (Camagni, 1995; Coppin et al., 2000) - may speed up the innovation processes then get the maximum benefits from cooperation without 
limiting the competition of each single firms. Eventually, given the role of international stevedoring operators within the market (e.g. APMT, HPH. DP World), it is important to underline that knowledge transfers could play a crucial role in innovative processes as well as in their assessment (Roumboutsos et al., 2016). Current research did not look at those aspects in detail - focusing more on the achievement of goals at local level - but it will represent a future research goal. First indications from one involved operator show that such knowledge transfer within the wider company group is not evident (Carlan et al., 2017).

Anyway, further investigation should focus on the link among the actors involved in the innovation process in order to highlight specific interactions that might foster the innovation success in the deep-sea terminal industry.

\section{References}

Acciaro, M., and C. Sys. 2016, "Innovation along the maritime Supply Chain: Aligning Strategy with Outcomes." Proceedings of the IAME Annual Conference 2016, International Association of Maritime Economists, Hamburg, 23-26 August 2016.

Acciaro, M., Ghiara, H., and M.I. Cusano. 2014b. "Energy management in seaports: A new role for port authorities." Energy Policy 71: 4-12.

Acciaro, M., Vanelslander, T., Sys, C., Ferrari, C., Roumboutsos, A., Giuliano, G., Lam, J.S.L., and S. Kapros. 2014a. "Environmental sustainability in seaports: a framework for successful innovation." Maritime Policy \& Management 41 (5): 480-500.

Arduino, G., Aronietis, R., Crozet, Y., Frouws, K., Ferrari, C., Guihéry, L., Kapros, S., Kourounioti, I., Laroche, F., Lambrou, M., Lloyd, M., Polydoropoulou, A., Roumboutsos, A., Van de Voorde, E., and T. Vanelslander. 2013. "How to turn an innovative concept into a success? An application to seaport-related innovation." Research in Transportation Economics 42: $97-107$.

Arduino, G., Aronietis, R., Crozet, Y., Frouws, K., Ferrari, C., Guihéry, L., Kapros, S., Kourounioti, I., Laroche, F., Lambrou, M., Lloyd, M., Polydoropoulou, A., Roumboutsos, A., Van de Voorde, E., and Vanelslander, T. 2011a. "InnoSuTra Project Deliverable D6: Scenario Framework for Successful Innovation.” Antwerp, University of Antwerp.

Arduino, G., Carrillo, M.D., and C. Ferrari. 2011b. "Innovative evidences in maritime transport." In Proceedings of the international association of maritime economists (IAME) conference 2011, Santiago de Chile, October. 
Aronietis, R., Markianidou, P., Meersman, H., Pauwels, T., Van de Voorde, E., Vanelslander, T., et al. 2009. "Measures for improving capacity in port hinterland connections by road." In Proceedings of the European Transport Conference 2009, Noordwijkerhout, The Netherlands

Arrow, K. 1962. "Economic Welfare and the Allocation of Resources for Invention," In The Rate and Direction of Inventive Activity: Economic and Social Factors, National Bureau of Economic research. Princeton: Princeton University Press.

Bottasso, A., Conti, M., Ferrari, C., and A. Tei. 2014. "Ports and Regional development: a spatial analysis on a panel of European regions." Transportation Research Part A 65: 44-55.

Cahoon, S., Pateman, H., and S.H. Chen. 2013. "Regional port authorities: Leading players in innovation networks?” Journal of Transport Geography 27: 66-75.

Camagni, R. 1995. "The concept of innovative milieu and its relevance for public policies in European lagging regions.” Papers in Regional Science 74 (4): 317-340.

Cantner, U., Meder, A., and A. Wall. 2010. "Innovator networks and regional knowledge base." Technovation 30 (9): 496-507.

Carlan, V., Sys, C., Vanelslander, T. and A. Roumboutsos. 2017. "Digital innovation in the port sector: barriers and facilitators." Competition and regulation in network industries 18: 1-23. Coppens, F., Lagneaux, F., Meersman, H., Sellekaerts, N., Van de Voorde, E., Van Gastel, G., and A. Verhetsel. 2007. Economic Impacts of Port Activity: A Disaggregated Analysis, The Case of Antwerp. National Bank of Belgium, Working Paper Series.

Coppin, O., Ziel J., and N. Mudard. 2000. "Développement portuaire et milieu innovateur. Le cas de Dunkerque." Communication présentée au 5ème colloque international Littoral 2000, Cavtat-Dubrovnik (Croatie), 13-17 Septembre.

Cui, Q. 2017. "Environmental efficiency measures for ports: an application of RAM-Tobit-RAM with undesirable outputs." Maritime Policy \& Management, 44 (5): 551-564.

De Martino, M., Erricchello, L., Marasco, A., and A. Morvillo. 2013. "Logistics Innovation in Seaports: An inter-organizational perspective." Research in Transportation Business \& Management 8: 123-133.

Doloreux, D., and Y. Melancon. 2008. "On the dynamics of innovation in Quebec's coastal maritime industry." Technovation 28: 231-243.

Edquist, C., ed. 1997. Systems of Innovation, Technologies, Institutions and Organisations. London: Pinter.

Edquist, C. and C. Chaminade. 2006. "Industrial policy from a systems-of-innovation perspective." EIB Papers 11(1): 108-132. 
FISS, P. 2008. Using Qualitative Comparative Analysis (QCA) and Fuzzy Sets, http://professormurmann.info/index.php?ACT =24\&fid=11\&aid=56_oPhPCLjduXz7KtWCeJbr\&board_id=1

Gallouj F., and O. Weinstein. 1997. "Innovation in services." Research Policy 26: 537-556.

Giuliano, G., Knatz, G., Hutson, N., Sys, C., Vanelslander, T., and V. Carlan. 2016. "Decisionmaking for maritime innovation investments: The significance of cost benefit and cost effectiveness analysis" Working paper, University of Antwerp. Retrieved from https://www.uantwerpen.be/images/uantwerpen/container1244/files/TEW\%20-

\%20Onderzoek/Working\%20Papers/RPS/2016/RPS-2016-001.pdf

Hall, P. V., and W. Jacobs. 2010. "Shifting proximities: The maritime ports sector in an era of global supply chains." Regional Studies 44: 1103-1115.

Hipp, C., and H. Grupp. 2005. "Innovation in the service sector: The demand for service-specific innovation measurement concepts and typologies." Research Policy 34: 517-535.

ITF - International Transport Forum 2010. Transport and Innovation: Unleashing the Potential. Paris: OECD.

Jansen, J.J.P., Van Den Bosch, F.A.J., and H.W. Volberda. 2006. "Exploratory Innovation, Exploitative Innovation, and Performance: Effects of Organizational Antecedents and Environmental Moderators." Management Science 52 (11): 1661-1674.

Jenssen, J. 2003. "Innovation, capabilities and competitive advantage in Norwegian shipping." Maritime Policy \& Management 30 (2): 93-106.

Jiang, C., Wan, Y., and A. Zhang. 2017. "Internalization of port congestion: strategic effect behind shipping line delays and implications for terminal charges and investment." Maritime Policy \& Management 44 (1): 112-130.

Jick, T.D. 1979. "Mixing Qualitative and Quantitative Methods: Triangulation in Action." Administrative Science Quarterly, Qualitative Methodology 24(4): 602-611.

Kandampully, J. 2002. "Innovation as the core competency of a service organization: The role of technology, knowledge and networks." European Journal of Innovation Management 5: 18-26.

Kapros, S. 2010. "European transport policy instruments and actors' attitudes in specific markets: The case of motorways of the sea in the East Mediterranean." Proceedings European Transport Conference 2010, Glasgow, 11-13 October.

Lam, J.S.L., and E. Van de Voorde. 2012. "Green Port Strategy for Sustainable Growth and Development. In Transport Logistics for Sustainable Growth at a New Level”, Proceedings of the International Forum on Shipping, Ports and Airports (IFSPA), edited by T. L. Yip, X. Fu, and A.K.Y. Ng, Hong Kong, May 28-30: 417-427. Hong Kong: The Hong Kong Polytechnic University. 
Lam, J.S.L., and T. Notteboom. 2014. "The greening of ports: a comparison of port management tools used by leading ports in Asia and Europe." Transport Reviews 34 (2): 169-189.

Lundvall, B., ed. 2010. National systems of innovation: toward a theory of innovation and interactive learning. London: Anthem Press

Mothe, C., and N.T.T. Uyen. 2012. "The impact of non-technological on technological innovations: do services differ from manufacturing? An empirical analysis of Luxembourg firms." International Journal of Technology Management 57: 227-244.

Nelson, R.R. 1993. National Innovation Systems: A Comparative Study, Oxford: Oxford University Press.

Powel, W., and S. Grodal. 2005. "Networks of innovators." In The Oxford Handbook of Innovation, edited by J. Fagerberg, D. Mowery and R. Nelson. Oxford: Oxford University Press.

Rogers, E.M. 1962. Diffusion of innovations, New York, NY; The Free Press.

Roumboutsos, A. 2015. "Port Innovation, Comparative analysis of Cases - Systems' Innovation Approach.” University of Aegean BNPPF innovation event, Antwerp, February 2015.

Roumboutsos, A., Kapros, S., and T. Vanelslander. 2014. "Green city logistics: Systems of Innovation to assess the potential of E-vehicles." Research in Transportation Business and Management 11: 43-52.

Roumboutsos, A., Sys, C., and T. Vanelslander. 2016. "Imitation: Innovation made easy. Cases from the Port Sector." Paper presented at World Conference on Transport Research - WCTR 2016 Shanghai, July 10-15

Schumpeter, J.A. 1939. Business cycles (Vol. 1). New York: McGraw-Hill.

Stopford, M. 2015. "Shipping's smarter path: Stopford”, available at:

http://splash247.com/shippings-smarter-path-stopford/.

Sundbo, J. 1998. The theory of innovation: Entrepreneurs, technology and strategy. Cheltenham, UK: Edgar Elgar Publishing Limited.

Sys, C., Vanelslander, T., Acciaro, M., Ferrari, C., Roumboutsos, A., Giuliano, G., Lam, J., Knatz, G., and R. Macario. 2015a. "Executive summary." Retrieved from http://anet.be/record/opacirua/c:irua:127919

Sys, C., Vanelslander, T., and V. Carlan. 2015b. Innovative concepts in the maritime supply chain, Retrieved from

https://www.uantwerpen.be/images/uantwerpen/container2629/files/BNPPF/Sys_20150907_Inno vation\%20overview\%20stakeholders.pdf 
Sys, C., Vanelslander, T., Roumboutsos, A., Giuliano, G., and M. Acciaro. 2016. Port related innovation: the answer to today's constraints and challenges in seaports related operations. Antwerp: University of Antwerp.

Thiem, A., and A. Dusa. 2013. "QCA: A Package for Qualitative Comparative Analysis." The $R$ Journal 5 (1): 87-97.

Thorpe, N., and A. Namdeo. 2016. "Innovations in Technologies for Sustainable Transport." Research in Transportation Business and Management 18: 1-3.

Vanelslander, T., Sys, C., and V. Carlan. 2016. "Innovation among seaport operators: a QCA approach for determining success conditions." International Journal of Transport Economics XLIII (3): 289-312.

Volderba, H. 2014. "Social innovation is of pivotal importance to top-priority economic sectors in the Netherlands" available at: https://www.rsm.nl/about-rsm/news/detail/3108-socialinnovation-is-of-pivotal-importance-to-top-priority-economic-sectors-in-the-netherlands/.

Woolthuis, R. K., Lankhuizen, M., and V. Gilsing. 2005. "A System Failure Framework for Innovation Policy Design.” Technovation 25: 609-619.

Zheng, S., and R.R. Negenborn. 2017. "Terminal investment timing decisions in a competitive setting with uncertainty using a real option approach." Maritime Policy \& Management 44 (3): $392-411$. 